\title{
Proposed Methodology for End-of-Life Option using Multi Criteria Decision Analysis: A Study for General Paper Product
}

\author{
Salwa Mahmood ${ }^{1 *}$, Muhammad Aizrul Ezuan Edirudzin ${ }^{1}$ and Nur Syamimi Jiran ${ }^{2}$ \\ ${ }^{1}$ Department of Mechanical Engineering Technology, Faculty of Engineering Technology, Universiti Tun \\ Hussein Onn Malaysia, Pagoh Campus, KM 1 Jalan Panchor, 84600 Pagoh, Johor, Malaysia \\ ${ }^{2}$ School of Mechanical Engineering, Faculty of Engineering, Universiti Teknologi Malaysia, 81310 Skudai, \\ Johor Bahru, Johor, Malaysia
}

\begin{abstract}
Over the years, the world population has been growing exponentially. This population growth affects the number of waste products due to the increased production, which leads to greater environmental impact and other problems. There are different numbers of product end-of-life (EOL) options to handle waste based on product characteristics. This research is designed to develop a methodology to determine the best EOL option for a paper product using the analytical hierarchy process (AHP). AHP is one of the multi-criteria decision analysis (MCDA) methods employed to select the best option by considering the user's preferences and output of competing EOL options related to different product criteria. A graphical user interface (GUI) called AHP-based software was developed using Microsoft Excel through the programming function of Visual Basic for Applications as a user facilitating tool when conducting the analysis. The case study technique is applied to five different types of paper products to assess the capability of the proposed AHP-based software. Results from the AHP-based software reveal that recycling is the most suitable EOL technique for most paper products compared to other techniques. However, polluted products with ink or food waste and coating may not be suitable for this method. The research assists the users to identify the most sustainable ways to handle paper product waste based on the product condition.
\end{abstract}

ARTICLE INFO

Article history:

Received: 05 May 2021

Accepted: 05 August 2021

Published: 28 October 2021

DOI: https://doi.org/10.47836/pjst.29.4.40

E-mail addresses:

msalwa@uthm.edu.my (Salwa Mahmood)aizrule@gmail.com

(Muhammad Aizrul Ezuan Edirudzin)

syamimi.jiran@gmail.com (Nur Syamimi Jiran)

* Corresponding author
Keywords: Analytical hierarchy process, end-of-life, multi-criteria decision analysis, paper product

\section{INTRODUCTION}

The increase in the human population indirectly causes the demand for products to continue rising (Jiran et al., 2019). 
However, products lifespan is declining to cope with the recent technologies and trends. Rapid production and advanced manufacturing technology to meet consumer demand indirectly affect the environment and produce much solid waste. In addition, unsustainable consumption and production patterns have resulted in increased waste generation over many decades (Vlachokostas et al., 2021). The impact of a high production process can lead to the environmental effect of products through their entire life cycle (Gehin et al., 2008). Solid Waste Management (SWM) is a global problem, particularly in emerging industrial countries, including Malaysia (Badgie et al., 2012). According to the UN, global waste generation is projected to double between 2016 and 2050 (Nation, 2019). Although increased waste generation is indirectly caused by urbanisation and rising living standards (Arikan et al., 2017; Ibrahim et al., 2017) developed countries generate more solid waste than developing countries (Sekhon \& Karthigesu, 2017). For example, Malaysia's waste generation is estimated at 38,000 metric tons per day (Lim, 2018) and is predicted to increase by $3 \%$ annually (Badgie et al., 2012).

Due to inadequate suitable technology, manpower, land scarcity and waste facilities in Malaysia (Badgie et al., 2012; Zainu \& Songip, 2017), SWM is becoming one of the most critical environmental issues (Kharat et al., 2019) and also requiring a major commitment (Rahman et al., 2020) to deal with the rapid increase in waste generation in line with human population growth (Ibrahim et al., 2017). More than $80 \%$ of solid waste is disposed of in landfills and open dumps (Liu et al., 2017; Rahman et al., 2020), while only 20\% is recycled (Jereme et al., 2015). The low recycling percentage is due to low cooperation in the recycling activity and solid waste separation at the source (Moh \& Manaf, 2017). The Malaysian Recycle Program was first launched in 1993 (Rahman et al., 2020) and then launched second in the 8th Malaysian Plan (2001-2005) by the Government with elements for minimising waste, promoting re-use activities and developing several pilot projects for the recycling program (Zainu \& Songip, 2017). The 3R (i.e. reuse, reduce, recycle) campaign is part of this plan and was introduced in 2005 through the National Strategic Plan for Solid Waste Management (Rahman et al., 2020).

The European Union has established a waste management hierarchy as a guideline for waste management, consisting of 5 steps (Commission, 2008), i.e. prevention, reuse, recycle, recovery and disposal. Prevention is the first step and the best option for waste management (Ismail \& Hanafiah, 2017), starting with the product before it is converted into waste. Prevention refers to reducing and restricting several hazardous materials and shifting the use to a safer material option (Ongondo et al., 2011). In addition, it may also refer to the reduction of total waste generation as early as during the product fabrication (Ahmadi, 2017; Rahman et al., 2020). Manufacturers are responsible for producing products from environmentally friendly materials and are encouraged to dispose of the products safely and properly (Ismail \& Hanafiah, 2017; Rahman et al., 2020). Reuse is the best option 
for EOL (Ahmadi, 2017) in which it refers to continuous usage of the product multiple times before it can be disposed of, such as the use of a bio-bag or a recycling bag while shopping, rather than a single-use of plastic bag (Ahmadi, 2017). Reuse can also be applied by selling, donating or repairing the product for it to be used by others, thus extending the product's life and reducing the generation of waste (T'ing et al., 2020). Recycle is the activity of collecting, separating and processing waste (paper, plastic metal and glass) into a new valuable product (T'ing et al., 2020; Rahman et al., 2020). Disposal at the landfill site is the last option in the waste management hierarchy, and the use should be minimised.

Disposal at the landfill sites continues to be the main option for SWM in Malaysia (Arifin et al., 2021; Ibrahim et al., 2017; Rahman et al., 2020; Samad et al., 2017). Unfortunately, improper SWM sites directly harm biodiversity, contributing to pollution, loss of ecotourism amenities, loss of aesthetic scenery, and cause explosion hazards (Ahmadi, 2017; Arifin et al., 2021; Badgie et al., 2012). Moreover, numerous illegal dumping sites throughout Malaysia worsens the situation as SWM in Malaysia is driven by profit and economic incentives with low dumping costs while ignoring environmental impacts (Mah et al., 2018). Improper and unsanitary SWM sites, as well as illegal dumpsites, cause visual pollution, which has an indirect impact on the quality of life in the community, as well as the economic, health and wellness of human beings (Ibrahim et al., 2017; Jayaraman et al., 2019; Matsakas et al., 2017; Samad et al., 2017). In addition, incineration or waste-toenergy is a waste-handling technology commonly used in developed countries to dispose of hazardous waste (Kumar \& Samadder, 2017). In Malaysia, this technology is used in the islands of Langkawi, Pangkor, Tioman, and Labuan (Rahman et al., 2020) to reduce waste transport costs to the mainland and handle clinical waste only in specific states. However, this technology is still being developed, and the operation is prohibitively expensive (Rahman et al., 2020). Composition is a common EOL option used by Malaysians, but it is still underutilised. Gathered leaves, yard waste, and food waste will be separated by compost microorganisms (Ar1kan et al., 2017) to improve the structure and $\mathrm{pH}$ of the soil and provide nutrients to the soil (Rahman et al., 2020).

A poor SWM system may also contribute to the depletion of natural resources (Rahman et al., 2020). Furthermore, due to the lack of available space for a new landfill site, the landfill cannot be the primary option for product EOL (Arıkan et al., 2017; Ibrahim et al., 2017; Randazzo et al., 2018). As a result, an effective SWM system is vital for maintaining the ecosystem and giving other benefits to the community, as well as lowering the waste management cost (Kharat et al., 2019; Rahman et al., 2020). Aside from that, implementing the $3 \mathrm{R}$ concept may help improve the SWM system and reduce the total waste generation in Malaysia, paving the way for sustainable SWM (Ahmadi, 2017; Badgie et al., 2012; Jayaraman et al., 2019; Jereme et al., 2015). A sustainable SWM should be environmentally friendly, economically feasible, and socially acceptable (Kharat et al., 2019). Another 
advantage of the $3 \mathrm{R}$ concept is that it reduces the greenhouse effect, reduces air, water, and land pollution, and increases natural resources. It is consistent with the goal of sustainable SWM, which is to balance the ecological system by recovering more products from waste with less energy usage and more positive environmental impacts (Badgie et al., 2012; Kharat et al., 2019; Sarigiannis et al., 2021). Education and awareness campaigns, particularly at the early age of education, can help to reduce waste generation (Zainu \& Songip, 2017). According to a study conducted by T'ing et al. (2020), attitude, facility, and habit contribute to the success of a recycling campaign among Malaysians.

Malaysia is one of the developing countries that is still trying to find the best way to manage and dispose of waste (Sekhon \& Karthigesu, 2017). Multi-criteria Decision Analysis (MCDA) has become critical because the problem is currently complex but must be resolved quickly and effectively (Mamat et al., 2018), including to solve SWM problems (Coban et al., 2018). MCDA is a versatile method for determining optimal outcomes (Kumar \& Samadder, 2017) that explicitly reflect numerous, multiple priorities while aggregating incomparable value (Coelho et al., 2017), and it can be combined with other tools such as life cycle assessment (LCA) (Vlachokostas et al., 2021). Moreover, compared to other decision-making support systems, it provides more robust decisions (Vlachokostas et al., 2021).

MCDA can be used to recognise among the most preferred options, rank options, short-list a limited number of options for further consideration, or distinguish acceptable options from unacceptable options (Achillas et al., 2013). As a result, it may be useful in assisting the strategy teams in planning and identifying high-value strategic options (Coelho et al., 2017). There are many different types of MCDA procedures, and each method has its characteristics. Some MCDA procedures are better suited for specific situations than others (Coelho et al., 2017). The methods are shown as follows:

- Weighted sum model (WSM)

- Weighted product model (WPM)

- Analytical hierarchy process (AHP)

- Preference ranking organisation method for enrichment evaluation (PROMETHEE)

- Elimination and choice translating reality (ELECTRE)

- Technique for order preference by similarity to ideal solution (TOPSIS)

- Compromise programming (CP)

- Multi-attribute utility theory (MAUT)

AHP is a type of MCDA method proposed by Prof Thomas Saaty in the 1970s (Dos Santos et al., 2019; Qazi et al., 2018) for solving complex and irregular decision-making problems using a hierarchical structure of criteria and alternatives (Abadi et al., 2018). AHP is the most commonly used MCDA technique (Badi et al., 2019; Coelho et al., 2017; Qazi et al., 2018; Vlachokostas et al., 2021) because it is an efficient approach for resolving 
a complex problem and is able to assist decision-makers in setting priorities and making the best decision (Qazi et al., 2018). AHP is an approach that evaluates alternatives using pairwise comparisons (Coelho et al., 2017) to determine a result based on the hierarchical relationship between factors, attributes, characteristics, or alternatives in the decisionmaking environment (Abadi et al., 2018). However, judging pairwise scales is a difficult part (Torkayesh et al., 2021), so it must be done under the supervision of an expert (Qazi et al., 2018). According to Subramanian and Ramanathan (2012), most of the previous AHP studies is an application and case-study basis before the proposed AHP model being used in the real-life problem. AHP-model had used in various problems such as selecting notebook (Abadi et al., 2018), identify solid waste treatment (Badi et al., 2019), an evaluation tool for end-of-life vehicles (Mamat et al., 2018), selection of MSW treatment and disposal technology (Kharat et al., 2019) and many more. AHP-model can be used for decisionmaking of various life problems from simple with multiple alternatives up to complex criteria and many choices of alternatives.

Several studies on EOL have been conducted in recent years, using various techniques such as AHP (Badi et al., 2019; Ghazalli \& Murata, 2011; Mamat et al., 2018), LCA (Ismail \& Hanafiah, 2017; Mah et al., 2018; Sarigiannis et al., 2021), MCDA (Achillas et al., 2013; Coelho et al., 2017; Qazi et al., 2018; Schwenk et al., 2012), TOPSIS (Büyüközkan \& Gocer, 2017; Yadav et al., 2020), and combining several methods (Coban et al., 2018; Torkayesh et al., 2020). However, most EOL studies in Malaysia focus on vehicle EOL (Ahmed et al., 2016; Mamat et al., 2018; Wong et al., 2018), e-waste (Ismail \& Hanafiah, 2017; Jayaraman et al., 2019; Kalana, 2010) and a review of the current state of EOL activity in Malaysia, with several recommendations for successful EOL SWM in Malaysia (Badgie et al., 2012; Ismail \& Hanafiah, 2017; Rahman et al., 2020; Zainu \& Songip, 2017). Paper product production and consumption are declining, but because their lifespan is short, they have become one of the major components of solid waste generation (Vukoje \& Rožić, 2018). It contributes to $7 \%$ of Malaysian total waste generation (Manaf et al., 2009; Zainu $\&$ Songip, 2017) apart from food, plastic, iron and glass that weighed up to $80 \%$ of total waste weight (Badgie et al., 2012; Kathirvale et al., 2004).

There are many different types of paper available, and for a variety of reasons, some of them can be recycled while others cannot. Normally, the EOL option for the paper product is incineration, non-recovery, landfill and boiler ash for industrial paper waste (van Ewijk et al., 2017). Choosing the best EOL option is difficult because there are many options and multiple criteria to consider (Kharat et al., 2019). Several researchers investigated the EOL option for paper products using various methods, but only a few used the MCDA method. Mostly developed methodologies do not consider the material, ecological, economic and social parameters to decide product EOL. Failure to select the best waste EOL option may exacerbate the SWM scenario (Torkayesh et al., 2021). Therefore, the 
goal of this research is to develop a graphical user interface (GUI) of the methodology for determining product paper EOL options using the AHP method while considering resources, environmental impacts, economic benefit and legislative significance, which are the three pillars of sustainability (Ahmad et al., 2018; Coelho et al., 2017; Colapinto et al., 2019). These include both quantitative and qualitative measures. The proposed methodology will also be validated using a case study of a paper product to demonstrate the capability and applicability of the GUI in providing end-users with guidelines for paper EOL options.

\section{MATERIAL AND METHOD}

\section{Proposed Methodology}

The proposed methodology employs the AHP method to determine the best EOL option for different paper products based on several criteria. Figure 1 shows the proposed methodology of this study. Firstly, set the goal to achieve, criteria as a boundary or requirement that need to fulfil and lastly listed the alternative options to be chosen. Next, identify any sub-criteria that may exist. Finally, draw the structural hierarchy and list all elements (options) and criteria for comparing all alternatives to mapping the problem. This study's AHP structure consists of four criteria: resource, environmental impact, economic value, and legislative priority, and five options: recycle, remanufacturing, reuse, incineration, and landfill. Table 1 lists the components of the AHP steps.

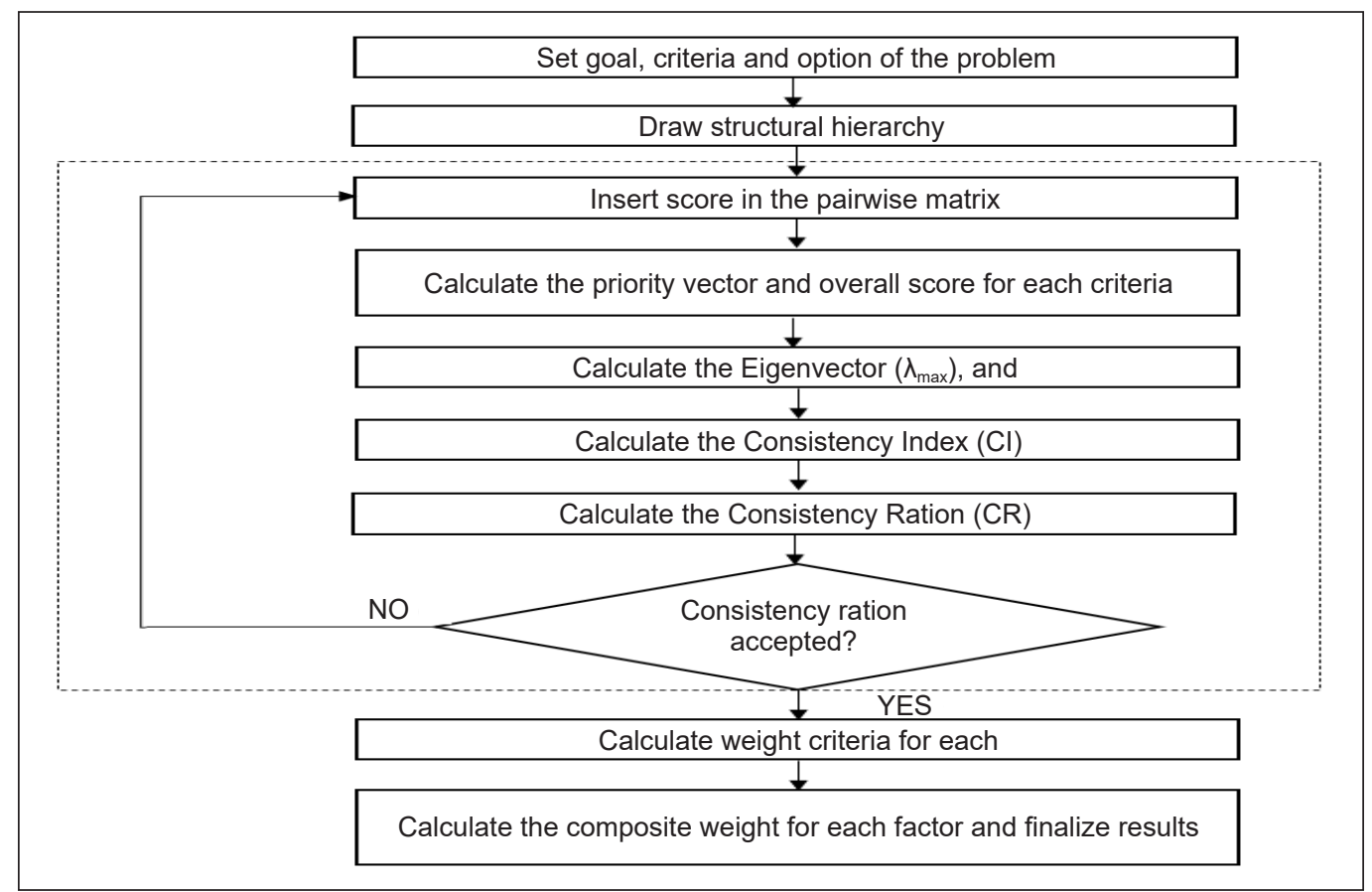

Figure 1. Flowchart of the proposed methodology of the study 
Table 1

AHP conceptual reference of alternatives selection criteria

\begin{tabular}{ll}
\multicolumn{1}{c}{ Step } & \multicolumn{1}{c}{ Dimension of Ranking } \\
\hline Objective & The vision or mission to do and develop. \\
Alternative & The types of vision or mission. \\
Criteria & The explanation of reason to choose that alternative. \\
\hline
\end{tabular}

The following steps are involved the AHP method. The basic steps for conducting AHP are defining the objective into a hierarchical model, determining weights for each criterion, calculating the score of each criterion's alternatives, and finally calculating each alternative's overall score (Kumar \& Samadder, 2017). AHP fulfils the SWM assessment requirements because, in the waste management context, criterion weights are frequently defined by the researcher's judgment (Coelho et al., 2017) while ignoring other factors. Since comparing elements in the evaluation is one of the most critical steps in AHP, it has become one of the most common and commonly used decision-making methods (Mamat et al., 2018). The AHP method usually applies numerical analysis to the pairwise comparison matrix in two steps, as stated below:

- Scoring: a numerical score on the strength of the preference scale for each option for each criterion is allocated to the predicted consequences of each option.

- Weighting: numerical weights are allocated to describe the relative values of a change between the top and bottom of the selected scale for each criterion.

The next step is to determine the pairwise score, which compares alternatives or variables depending on the analysis's target (Qazi et al., 2018; Randazzo et al., 2018). A pairwise comparison matrix is formed on the basis of the scores given for each of the components as input for the qualitative information. Pairwise comparisons on a scale of 1-9 are shown in Table 2. The decision maker's correlations are set in reciprocal matrices in pairwise comparison (Ahmadi, 2017). The diagonal elements of the matrix are 1. For example, a basic AHP application involving a number of I alternatives assessed by a total of $\mathrm{J}$ criteria can be represented by a comparison matrix of I rows and $\mathrm{J}$ columns, where Aij corresponds to the score of the jth criteria for the ith alternative evaluated (Coelho et al., 2017). The value in the proportional (Aji) can be calculated using the following formula in Equation 1. For example, the value of Aij is 5, so the value for Aji is 1/5 based on Equation 1.

$$
\mathrm{Aij}_{=} 1 / \mathrm{Aji}
$$

Then, for each criterion, the priority vector and summation are computed. The Eigenvector $\left(\lambda_{\max }\right)$ will be calculated using both elements. The maximum Eigenvector is equal to the number of correlations for a consistent reciprocal matrix that can be calculated using Equation 2: 


$$
\lambda_{\text {max }}=\sum \text { (priority vector } \times \text { sum of criteria) }
$$

The Consistency Index (CI) is a metric of consistency used as a variance or degree of consistency using the formula shown in Equation 3. CI is used to calculate the Consistency Ratio (CR) as CR is a comparison between CI and random consistency index (RI) as tabulated in Table 3. CR can be calculated using Equation 4. It is necessary to determine the CR for which the appropriate value should be less than $10 \%$ or else, judgments of pairwise score need to be revised (Saaty, 2008). The accuracy ratio indicates how accurate the user's judgments are. The CR value will be close to zero if the decisions are close to each other. Option comparison is chosen based on the result of the weight ratio scale of each criterion comparison. The highest result will be the best option compared to other options.

$$
\begin{aligned}
& \text { Consistency Index }(\mathrm{CI})=\frac{\left(\lambda_{\max }\right) \cdot-\mathrm{n}}{n-1} \\
& \text { Consistency Ratio }(\mathrm{CR})=\frac{\text { Consistency Index }(\mathrm{CI})}{\text { Random Consistency Index (RI) }}
\end{aligned}
$$

Repeat the AHP steps for each different type of product. Next, calculate the adjusted weight criteria (in ratio 1) for each criterion if the value of priority vector of any criterion

Table 2

Evaluation scales of pairwise comparison

\begin{tabular}{cll}
$\begin{array}{c}\text { Intensity of } \\
\text { Importance }\end{array}$ & \multicolumn{1}{c}{ Definition } & \\
\hline 1 & Equal Importance & Two activities contribute equally to the objective \\
2 & Weak or slight & N/A \\
3 & Moderate importance & $\begin{array}{l}\text { Experience and judgment slightly favor one activity over } \\
\text { another }\end{array}$ \\
& Noderate plus & N/A \\
4 & Strong importance & $\begin{array}{l}\text { Experience and judgment strongly favor one activity over } \\
\text { another }\end{array}$ \\
& Strong plus & $\begin{array}{l}\text { N/A } \\
\text { An activity is favored very strongly over another; its } \\
\text { dominance demonstrated in practice }\end{array}$ \\
& Very strong or & N/A \\
9 & Veryonstrated importance very strong & The evidence favoring one activity over another is of the \\
& Extreme importance & highest possible order of affirmation \\
\hline
\end{tabular}

Table 3

Random consistency index (Adopted from Saaty, 2008)

\begin{tabular}{lccccccccc}
\hline Size of matrix $(\mathrm{n})$ & 1 & 2 & 3 & 4 & 5 & 6 & 7 & 8 & 9 \\
\hline Random consistency index $(\mathrm{RI})$ & 0 & 0 & 0.58 & 0.90 & 1.12 & 1.24 & 1.32 & 1.41 & 1.45 \\
\hline
\end{tabular}


is small, or use the priority vector as the adjusted weight. Lastly, calculate the composite weight of each option by using Equation 5. The final results of the proposed methodology are in the form of a weight ratio preference scale. For example, the result for $\mathrm{X}$ is $38 \%$, $\mathrm{Y}$ is $49 \%$, and $\mathrm{Z}$ is $13 \%$. It indicates that $\mathrm{Y}$ weights 3.8 times more preference than $\mathrm{Z}$. meanwhile, $\mathrm{Z}$ has 1.3 times more preferable than $\mathrm{X}$.

$$
\text { Composite weight }=\sum(\text { scale } \times \text { adjusted weight criteria })
$$

\section{Graphical User Interface}

A graphical user interface (GUI) is a user interface functionality with electronic devices that visually represent the necessary commands and operating system or software device functions. For this project, GUI was developed using Microsoft Excel that employed a programming function of Visual Basic for Applications (VBA) based on the process of the AHP method. The developed software allows users to use various computational techniques and send the results back to the datasheet. VBA is an adaption of the eventdriven programming language in Microsoft Visual Basic. In this research, the user must click on the CALCULATE cell to generate the results for each option developed using the proposed methodology. In addition, AHP-based software was developed to evaluate the EOL options for the paper product that enabled the general public to access all kinds of systems for everyday use, regardless of their experience or knowledge.

The first step in developing the proposed GUI is to define the user and its requirement. The users of the proposed GUI are OEMs, remanufacturers, recyclers or government specialists, as a result of which there will be different inclinations to make a judgment. For example, manufacturers and recyclers may be more interested in optimising the resource and environmental impact as their main criteria when determining EOL products. As for government specialists, they may prefer the legislative priority and economic value as their main criteria.

Next, identify the problem that needs to be solved. Then, list the input, output and processing of the proposed software. Input is the list of source data supplied to the problem. Output is the list of required outcomes from the software. Meanwhile, the processing is the list of actions required to produce the required output. The list of input, processing and output of proposed AHP-based software is presented in Table 4.

After identifying the problem and expected outcome, the outline of the solution is presented, i.e. the developed methodology. As for this research, the steps in the proposed software are computation of pairwise matrix, computation of consistency ratio, and finalising the EOL option. The GUI will visually and numerically display the percentage of components of a particular EOL. Once the user is satisfied with the result, they can save the results by saving the Excel folder. 
Table 4

List of input, processing and output of the proposed AHP-based software

\begin{tabular}{|c|c|c|}
\hline Input & Processing & Output \\
\hline $\begin{array}{l}\text { Weightage of main criteria } \\
\text { (Resource, environmental } \\
\text { impact, economic value, } \\
\text { legislative priority). } \\
\text { - Judgments of performance } \\
\text { of } 5 \text { EOL option within each } \\
\text { criteria. }\end{array}$ & $\begin{array}{l}\text { - Computation of pairwise matrix. } \\
\text { - Computation of consistency ratio (CR). } \\
\text { - Computation of global priority of each } \\
\text { EOL option for each component of the } \\
\text { product. } \\
\text { - Computation of the percentage usage of } \\
\text { each EOL option based on number of } \\
\text { parts. }\end{array}$ & $\begin{array}{l}\text { - Preferred EOL option } \\
\text { for a component. } \\
\text { - Consistency and } \\
\text { acceptability of the } \\
\text { user's judgments. } \\
\text { - Important ratings of } \\
\text { EOL options based on } \\
\text { their percentage. }\end{array}$ \\
\hline
\end{tabular}

\section{Algorithm Testing for Correctness}

After developing the AHP-based software, the following step is to perform algorithm testing for correctness. The main aim of this phase is the early detection of major logical errors to be easily corrected. Test data must be walked through each step in the algorithm to ensure that the instruction defined in the algorithm does what it is supposed to do. For example, the data used to test the algorithm for calculating the pairwise matrix was a matrix of $4 \times 4$. The matrix values are shown in Table 5, with the resulting priority value and CR value in Table 6.
Table 5

Pre-defined data for testing (Adopted from Saaty, 2008)

\begin{tabular}{ccccc}
\hline & $\mathrm{A}$ & $\mathrm{B}$ & $\mathrm{C}$ & $\mathrm{D}$ \\
\hline $\mathrm{A}$ & 1.00 & 4.00 & 2.00 & 5.00 \\
$\mathrm{~B}$ & 0.25 & 1.00 & 0.33 & 4.00 \\
$\mathrm{C}$ & 0.50 & 3.00 & 1.00 & 4.00 \\
$\mathrm{D}$ & 0.20 & 0.25 & 0.25 & 1.00 \\
\hline
\end{tabular}

Table 6

Priorities of pre-defined data

\begin{tabular}{cccc}
\hline $\mathrm{A}$ & $\mathrm{B}$ & $\mathrm{C}$ & $\mathrm{D}$ \\
\hline $47.82 \%$ & $15.70 \%$ & $29.62 \%$ & $6.85 \%$ \\
\hline
\end{tabular}

$\mathrm{CR}=9.21 \%$

After checking with the developed algorithm, the results were found to match the desired results, as shown above, thus verifying that the algorithm developed is working as desired. The value was used for the main criteria in the program.

\section{Case Study Description}

A case study is used to demonstrate the efficacy of the proposed software, which uses the AHP as the optimisation method to find the best EOL option for paper products. It aids in the selecting the best EOL option for various types of paper products based on the user's criteria. The five types of paper products used in this study are offset, coated, newsprint, cardboard, and paperboard. All of this is common paper waste found in Malaysia. The criteria for determining the best EOL for each type of paper product are a resource, environmental impact, economic value, and legislative priority. Resources refer to the effects of the EOL alternative on the resource. Products made from scarce resources that are difficult to manufacture can necessitate alternatives to landfilling and incineration to ensure the best use 
of the resources. The environmental impact factor includes the effect on the environment, whether negative or positive, of human behaviour, commodity production, or operation in the plant. An economic benefit is a monetary indicator of a business person's benefit from a good or service. There are various waste management solutions available today, but the cost-benefit analysis of those technologies remains a major problem (Sarigiannis et al., 2021). The factor of legislative priority refers to the waste hierarchy framework, as previously stated. Waste should be reduced as early as in the product production process as possible. When a product becomes waste, landfill disposal should be the last alternative after exhausted all solutions such as recycling and minimising. In the meantime, the EOL options in this study are recycling, remanufacturing, reusing, incineration, and landfill.

\section{RESULTS AND DATA ANALYSIS}

\section{Proposed Methodology}

The proposed methodology was developed by using a computer datasheet in Microsoft Excel. This model consists of 5 layers of Excel worksheets consists of Main Criteria, Factor A Resource, Factor B Environmental Impact, Factor C Economic Value, Factor D Legislative Priority and Composite Weight. The following section will explain the features of the developed software that employed AHP as an optimisation method and the results generated from the developed software.

\section{AHP-based Software}

All calculation to determine the suitable option for a paper product that employed AHP analysis was developed using Microsoft Excel. Users are only required to key in the value for each criterion and the EOL option before clicking the CALCULATE button, and the result for the EOL option will appear. In this analysis, the criteria or factors considered are resources, environmental impact, economic value and legislative priority, as shown in Figure 2. Each factor would compute the $\lambda_{\max }$, CI and CR. Figure 3 shows an example of

\begin{tabular}{|c|c|c|c|c|c|}
\hline Product Name & & & & & \\
\hline & & & & & \\
\hline Main Criteria & Resource & Environmental Impact & Economic Value & Legistative Priority & Priority \\
\hline Resource & 1.00 & & & & \\
\hline Environmental Impact & & 1.00 & & & \\
\hline Economic Value & & & 1.00 & & \\
\hline Legistative Priority & & & & 1.00 & \\
\hline Sum & & & & & $100 \%$ \\
\hline & & & & & \\
\hline$\lambda \max$ & & & & & \\
\hline $\mathrm{Cl}$ & & & & & \\
\hline $\mathrm{CR}$ & & & & & \\
\hline
\end{tabular}

Figure 2. Main criteria 


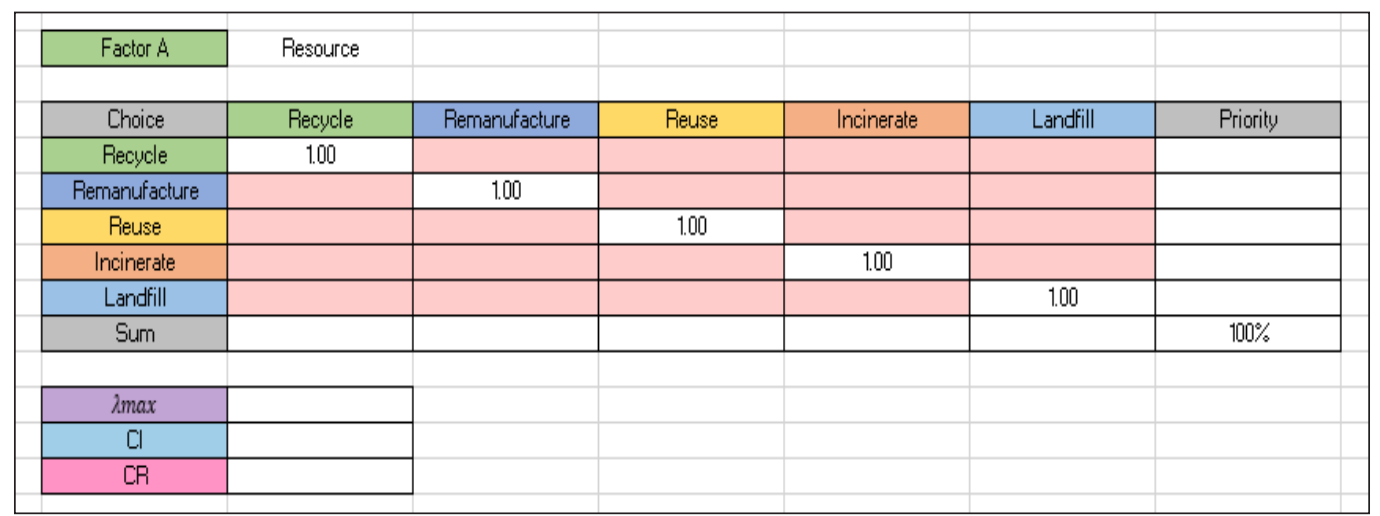

Figure 3. Resource

\begin{tabular}{|c|c|c|c|c|c|}
\hline \multicolumn{2}{|c|}{ Factor $\mathrm{A}$} & Factor $\mathrm{B}$ & Factor $\mathrm{C}$ & Factor D & Composite Weight \\
\hline Adjusted Weight & & & & & \\
\hline Recycle & & & & & \\
\hline Remanufacture & & & & & \\
\hline Reuse & & & & & \\
\hline Incinerate & & & & & \\
\hline Landfill & & & & \\
\hline \multicolumn{2}{|c|}{ Caculate } \\
\cline { 3 - 5 }
\end{tabular}

Figure 4. Composite weight

GUI for factor resource. The most suitable option for EOL product paper is illustrated in the composite weight as in Figure 4 in percentages. The highest percentage shows that it is the best solution as compared to other options.

\section{Results Analysis}

Offset, coated, newsprint, cardboard, and paperboard were chosen as case studies to test the capability of the established methodology in determining the most suitable EOL option. After judging all products, a list of composite weights for all products was generated, as shown in Table 7. The results show that, except for coated paper, the rest of the paper items can be recycled. The recycling option has a composite weight of $36.5 \%$ for offset, $35.48 \%$ for newsprint, $36.51 \%$ for cardboard and $38.38 \%$ for paperboard. Meanwhile, incineration has the maximum composite weight for coated paper at $32.68 \%$. It indicates that recycling offset paper is 0.365 times more preferable than reusing. Meanwhile, incineration is 0.3268 times more superior to a landfill for coated paper. For newsprint, recycle weights are 0.3548 times more preferable compared to incineration. When it comes to cardboard, recycling is 0.3651 times more preferable than remanufacturing. Finally, for paperboard, recycling is 0.3838 times more preferable than reusing. 
Table 7

Composite weight of paper product

\begin{tabular}{clccccc}
\hline No & Product & Recycle & Remanufacture & Reuse & Incinerate & Landfill \\
\hline 1 & Offset & $36.50 \%$ & $25.97 \%$ & $29.22 \%$ & $3.52 \%$ & $4.78 \%$ \\
2 & Coated & $18.46 \%$ & $8.47 \%$ & $13.47 \%$ & $32.68 \%$ & $26.91 \%$ \\
3 & Newsprint & $35.48 \%$ & $23.01 \%$ & $13.24 \%$ & $24.65 \%$ & $3.62 \%$ \\
4 & Cardboard & $36.51 \%$ & $32.68 \%$ & $21.31 \%$ & $5.54 \%$ & $3.97 \%$ \\
5 & Paperboard & $38.38 \%$ & $20.87 \%$ & $29.65 \%$ & $6.72 \%$ & $4.37 \%$ \\
\hline
\end{tabular}

\section{DISCUSSION}

The effective method of EOL for paper products is directly dependent on the relationship of papers and printing inks (Vukoje \& Rožić, 2018). According to the findings of the AHP-based software, most forms of paper products can be recycled during the EOL stage. Recycling is the method of storing and processing waste according to its type before producing a new product or reusing it for other purposes in the form of recycled materials or cardboard items (Jereme et al., 2015; Vukoje \& Rožić, 2018). However, coated paper is more likely to be incinerated or landfilled because it contains toxic materials that endanger human health and wellbeing (Vukoje \& Rožić, 2018). Aside from that, the manufacturer must take extra steps to strip the coating before it can be recycled. Therefore, it will increase the time required to recycle or remanufacture as well increasing the cost that has to be borne by the manufacturer.

Furthermore, if the paper has been covered with polyethene, the quality of recycling is poor. As a result, it is preferable to be incinerated to provide more energy (Vukoje \& Rožić, 2018). Recycling paper waste is a beneficial action (Vukoje \& Rožić, 2018) because it reduces the waste capacity for disposal at landfills or incineration, all of which cause pollution (Badgie et al., 2012; Joshi et al., 2017). In addition, the use of recycled materials in the manufacturing industry may minimise the amount of energy and resources required to create a new product (Vukoje \& Rožić, 2018), hence lowering the environmental effect on the ecosystem (Badgie et al., 2012; Jereme et al., 2015; Mah et al., 2018). Furthermore, recycling can be a secondary source of revenue for low-income people (Badgie et al., 2012; Rahman et al., 2020). However, recycling activity must be handled properly to prevent any negative consequences for the environment and the staff who handle the operation (Ismail \& Hanafiah, 2017; Mahmood et al., 2019; Sekhon \& Karthigesu, 2017; Vukoje \& Rožić, 2018).

On the other hand, papers that have been contaminated with other products, such as food juice or oil, should be disposed of or incinerated (Saraiva et al., 2016). Landfilling is still the most popular EOL solution in most developing countries, including Malaysia (Kumar \& Samadder, 2017), since it can handle almost any form of waste (Badgie et al., 
2012; Zainu \& Songip, 2017). Inefficient SWM in unsanitary landfills, on the other hand, can lead to other problems and different forms of pollution in the short and long term, in addition to the effects on human health and the environment (Assi et al., 2020; Das et al., 2019; Kumar \& Samadder, 2017; Rahman et al., 2020; Zainu \& Songip, 2017). Therefore, aside from landfills, incineration has become the most common EOL alternative among Malaysians (Badgie et al., 2012), as it can minimise waste volume by up to tenfold (Badgie et al., 2012). In practice, incineration is one of the most commonly used waste-to-energy technologies when dealing with waste that cannot be recycled (Vukoje \& Rožić, 2018), particularly in developed countries (Dong et al., 2018; Kumar \& Samadder, 2017), because it has very low operating costs when compared to other technologies (Almanaseer et al., 2020).

However, poor controls in incineration operations result in toxic chemicals such as dioxins being released into the air, soil, and water, which may have an impact on human health and the ecosystem (Randazzo et al., 2018; Sarigiannis et al., 2021; Zainu \& Songip, 2017). Nevertheless, the disadvantages of the incineration process such, as GHG emissions and environmental harm, can be overcome if the bottom ash is treated properly (Almanaseer et al., 2020). However, composting is more environmentally sustainable than incineration (Arikan et al., 2017). According to Das et al. (2019) and Qazi et al. (2018), composting reduces GHG emissions up to $47 \%$ compared to incineration. Furthermore, composting through organic recycling is appropriate for polluted paper products that cannot be recycled conventionally (Vukoje \& Rožić, 2018).

Rapid urban global growth leads to change in the human population and, as a result, causing a hike in waste production (Manaf et al., 2009; Samad et al., 2017). Therefore, it is essential to develop a sustainable SWM that creates a 'closed loop' waste cycle that focuses on reducing waste in order to conserve natural resources for future generations (Manaf et al., 2009) is needed. Waste generation must be treated and disposed of properly (Torkayesh et al., 2021), and one approach is through waste recycling. Waste recycling in Malaysia seems unsuccessful ( T'ing et al., 2020) within the first two years since it was implemented and is still developing. However, the percentage of waste recycled has risen and has reached the 2019 recycling goal (Rahman et al., 2020). Furthermore, educating the public about environmental consciousness, including proper recycling operation and waste separation at the source, enforcing waste regulations, designing an intelligent mechanism for managing the composition, and receiving support from the private waste management industry all lead to the effective adoption of sustainable SWM in Malaysia (Badgie et al., 2012; Jayaraman et al., 2019; T'ing et al., 2020; Manaf et al., 2009; Sarigiannis et al., 2021). Overall, customers must adjust their attitudes towards waste management at home and adapting it as a new social practice (Jayaraman et al., 2019). 


\section{CONCLUSION AND RECOMMENDATION}

In conclusion, the aim of the research, which is to develop an effective methodology for MCDA towards finding the best suitable alternative to treat EOL of the paper product, has been accomplished. The developed methodology focuses on evaluating and choosing the EOL options based on their compliance with all applicable criteria and considering the decision-maker's preferences. The methodology and AHP-based software were successfully developed using Microsoft Excel, and the AHP method is employed as the MCDA method of choice. This methodology had been validated by using a case study technique with various types of paper products. The judgments were delivered as a single decision-maker result, reflecting the OEM because of the easy nature of the product. The findings of the developed methodology indicate that recycling is the most preferred choice for almost all types of paper products due to the type of raw material used to manufacture the product.

However, some other products, especially polluted paper, may only be suitable for other techniques, including incineration. Nevertheless, to enhance the developed methodology, it is proposed that a group of decision-makers analyses the software to provide wider acceptability of decisions based on their preferences, and the outcome of the assessment will be more reliable. Furthermore, the software should be improved by removing values by adding the coding for the delete button to make it more user-friendly. Moreover, certain complex items require more parameters to be analysed, so it is crucial to enhance the coding to provide more than four criteria. Lastly, it can be seen that the major improvements involve the coding in Excel, which indicates that the improvement of GUI was needed to make the GUI easier and more user-friendly.

\section{ACKNOWLEDGEMENT}

The authors would like to thank the Ministry of Higher Education (MoHE), Universiti Tun Hussein Onn Malaysia and Universiti Teknologi Malaysia for funding this research work through the Collaborative Research Grant funding number K263.

\section{REFERENCE}

Abadi, S., Huda, M., Basiron, B., Ihwani, S. S., Jasmi, K. A., Hehsan, A., Safar, J., Mohamed, A. K., Embong, W. H. W., Mohamad, A. M., Noor, S. S. M., Novita, D., Maseleno, A., Irviani, R., Idris, M., \& Muslihudin, M. (2018). Implementation of fuzzy analytical hierarchy process on notebook selection. International Journal of Engineering and Technology, 7(1), 238-243. https://doi.org/10.14419/IJET.V7I2.27.12047

Achillas, C., Moussiopoulos, N., Karagiannidis, A., Banias, G., \& Perkoulidis, G. (2013). The use of multicriteria decision analysis to tackle waste management problems: A literature review. Waste Management \& Research, 31(2), 115-129. 
Ahmad, S., Wong, K. Y., Tseng, M. L., \& Wong, W. P. (2018). Sustainable product design and development: A review of tools, applications and research prospects. Resources, Conservation and Recycling, 132, 49-61. https://doi.org/10.1016/j.resconrec.2018.01.020

Ahmadi, M. (2017). Evaluating the performance of 3Rs waste practices: Case study-region one municipality of Tehran. Advances in Recycling and Waste Management, 2(130), 1-6. https://doi.org/10.4172/24757675.1000130

Ahmed, S., Ahmed, S., Shumon, M. R. H., Falatoonitoosi, E., \& Quader, M. A. (2016). A comparative decisionmaking model for sustainable end-of-life vehicle management alternative selection using AHP and extent analysis method on fuzzy AHP. International Journal of Sustainable Development \& World Ecology, 23(1), 83-97. https://doi.org/10.1080/13504509.2015.1062814

Almanaseer, N., Abbassi, B., Dunlop, C., Friesen, K., \& Nestico-Semianiw, E. (2020). Multi-criteria analysis of waste-to-energy technologies in developed and developing countries. Environmental Research, Engineering and Management, 76(1), 32-43. https://doi.org/10.5755/j01.erem.76.1.25254

Arifin, M. H., Kayode, J. S., Ismail, M. K. I., Abdullah, A. M., Embrandiri, A., Nazer, N. S. M., \& Azmi, A. (2021). Environmental hazard assessment of industrial and municipal waste materials with the applications of RES2-D method and 3-D Oasis Montaj modeling: A case study at Kepong, Kuala Lumpur, Peninsula Malaysia. Journal of Hazardous Materials, 406, Article 124282. https://doi.org/10.1016/j. jhazmat.2020.124282

Arıkan, E., Şimşit-Kalender, Z. T., \& Vayvay, Ö. (2017). Solid waste disposal methodology selection using multi-criteria decision making methods and an application in Turkey. Journal of Cleaner Production, 142, 403-412. https://doi.org/10.1016/j.jclepro.2015.10.054

Assi, A., Bilo, F., Zanoletti, A., Ponti, J., Valsesia, A., La Spina, R., Zacco, A., \& Bontempi, E. (2020). Zerowaste approach in municipal solid waste incineration: Reuse of bottom ash to stabilize fly ash. Journal of Cleaner Production, 245, Article 118779. https://doi.org/10.1016/j.jclepro.2019.118779

Badgie, D., Samah, M. A. A., Manaf, L. A., \& Muda, A. (2012). Assessment of municipal solid waste composition in Malaysia: Management, practice, and challenges. Polish Journal of Environmental Studies, 21(3), 539-547.

Badi, I., Abdulshahed, A., Shetwan, A., \& Eltayeb, W. (2019). Evaluation of solid waste treatment methods in Libya by using the analytic hierarchy process. Decision Making: Applications in Management and Engineering, 2(2), 19-35. https://doi.org/10.31181/dmame1902038b

Büyüközkan, G., \& Gocer, F. (2017). An intuitionistic fuzzy MCDM approach for effective hazardous waste management. In Intelligence systems in environmental management: Theory and applications (pp. 2140). Springer.

Coban, A., Ertis, I. F., \& Cavdaroglu, N. A. (2018). Municipal solid waste management via multi-criteria decision making methods: A case study in Istanbul, Turkey. Journal of Cleaner Production, 180, 159-167. https://doi.org/10.1016/j.jclepro.2018.01.130

Coelho, L. M. G., Lange, L. C., \& Coelho, H. M. (2017). Multi-criteria decision making to support waste management: A critical review of current practices and methods. Waste Management \& Research, 35(1), $3-28$. 
Colapinto, C., Jayaraman, R., Abdelaziz, F. B., \& La Torre, D. (2019). Environmental sustainability and multifaceted development: Multi-criteria decision models with applications. Annals of Operations Research, 293, 405-432. https://doi.org/10.1007/s10479-019-03403-y

Commission, E. (2008). Directive 2008/98/EC on waste (Waste Framework Directive). European Commission.

Das, S., Lee, S. H., Kumar, P., Kim, K. H., Lee, S. S., \& Bhattacharya, S. S. (2019). Solid waste management: Scope and the challenge of sustainability. Journal of Cleaner Production, 228, 658-678. https://doi. org/10.1016/j.jclepro.2019.04.323

Dong, J., Tang, Y., Nzihou, A., Chi, Y., Weiss-Hortala, E., Ni, M., \& Zhou, Z. (2018). Comparison of wasteto-energy technologies of gasification and incineration using life cycle assessment: Case studies in Finland, France and China. Journal of Cleaner Production, 203, 287-300. https://doi.org/10.1016/j. jclepro.2018.08.139

Dos Santos, P. H., Neves, S. M., Sant'Anna, D. O., Oliveira, C. H. d., \& Carvalho, H. D. (2019). The analytic hierarchy process supporting decision making for sustainable development: An overview of applications. Journal of Cleaner Production, 212, 119-138. https://doi.org/10.1016/j.jclepro.2018.11.270

Gehin, A., Zwolinski, P., \& Brissaud, D. (2008). A tool to implement sustainable end-of-life strategies in the product development phase. Journal of Cleaner Production, 16(5), 566-576. https://doi.org/10.1016/j. jclepro.2007.02.012

Ghazalli, Z., \& Murata, A. (2011). Development of an AHP-CBR evaluation system for remanufacturing: End-of-life selection strategy. International Journal of Sustainable Engineering, 4(01), 2-15. https://doi. org/10.1080/19397038.2010.528848

Ibrahim, T. N. T., Mahmood, N. Z., \& Othman, F. (2017). Estimation of leachate generation from MSW landfills in Selangor. Environmental Science, 19(1), 43-48.

Ismail, H., \& Hanafiah, M. M. (2017). Management of end-of-life electrical and electronic products: The challenges and the potential solutions for management enhancement in developing countries context. Acta Scientifica Malaysia (ASM), 1(2), 5-8. https://doi.org/10.26480/asm.02.2017.05.08

Jayaraman, K., Vejayon, S., Raman, S., \& Mostafiz, I. (2019). The proposed e-waste management model from the conviction of individual laptop disposal practices-An empirical study in Malaysia. Journal of Cleaner Production, 208, 688-696. https://doi.org/10.1016/j.jclepro.2018.10.125

Jereme, I. A., Alam, M. M., \& Siwar, C. (2015). Waste recycling in Malaysia: Transition from developing to developed country. Indian Journal of Education and Information Management, 4(1), 1-14.

Jiran, N. S., Gholami, H., Mahmood, S., Mat Saman, M. Z., Yusof, N. M., Draskovic, V., \& Jovovic, R. (2019). Application of activity-based costing in estimating the costs of manufacturing process. Transformations in Business \& Economics, 18(2B), 839-860.

Joshi, G., Naithani, S., Varshney, V. K., Bisht, S. S., \& Rana, V. (2017). Potential use of waste paper for the synthesis of cyanoethyl cellulose: A cleaner production approach towards sustainable environment management. Journal of Cleaner Production, 142, 3759-3768. https://doi.org/10.1016/j. jclepro.2016.10.089 
Kalana, J. A. (2010). Electrical and electronic waste management practice by households in Shah Alam, Selangor, Malaysia. International Journal of Environmental Sciences, 1(2), 63-75.

Kathirvale, S., Yunus, M. N. M., Sopian, K., \& Samsuddin, A. H. (2004). Energy potential from municipal solid waste in Malaysia. Renewable Energy, 29(4), 559-567. https://doi.org/10.1016/J.RENENE.2003.09.003

Kharat, M. G., Murthy, S., Kamble, S. J., Raut, R. D., Kamble, S. S., \& Kharat, M. G. (2019). Fuzzy multicriteria decision analysis for environmentally conscious solid waste treatment and disposal technology selection. Technology in Society, 57, 20-29. https://doi.org/10.1016/j.techsoc.2018.12.005

Kumar, A., \& Samadder, S. R. (2017). A review on technological options of waste to energy for effective management of municipal solid waste. Waste Management, 69, 407-422. https://doi.org/10.1016/j. wasman.2017.08.046

Lim, R. (2018, September 9). Green way to manage waste. The Star. https://www.thestar.com.my/news/ nation/2018/09/09/green-ways-to-manage-wasteswcorp-goes-for-green-technology-and-educating-theyoung/.

Liu, C., Hotta, Y., \& Totoki, Y. (2017). State of 3Rs in Asia and the Pacific country report: Malaysia. United Nations Centre for Regional Development

Mah, C. M., Fujiwara, T., \& Ho, C. S. (2018). Life cycle assessment and life cycle costing toward eco-efficiency concrete waste management in Malaysia. Journal of Cleaner Production, 172, 3415-3427. https://doi. org/10.1016/j.jclepro.2017.11.200

Mahmood, S., Hardan, M. N., Samat, M. K., Jiran, N. S., \& Shaari, M. F. (2019). Ergonomic posture assessment of butchers: A small enterprise study in malaysia food industry. Jurnal Teknologi, 81(6), 89-102. https:// doi.org/10.11113/JT.V81.13615

Mamat, T. N. A., Saman, M. Z. M., Sharif, S., Simic, V., \& Wahab, D. A. (2018). Development of a performance evaluation tool for end-of-life vehicle management system implementation using the analytic hierarchy process. Waste Management \& Research, 36(12), 1210-1222.

Manaf, L. A., Samah, M. A. A., \& Zukki, N. I. M. (2009). Municipal solid waste management in Malaysia: Practices and challenges. Waste Management, 29(11), 2902-2906. https://doi.org/10.1016/j. wasman.2008.07.015

Matsakas, L., Gao, Q., Jansson, S., Rova, U., \& Christakopoulos, P. (2017). Green conversion of municipal solid wastes into fuels and chemicals. Electronic Journal of Biotechnology, 26, 69-83. https://doi. org/10.1016/j.ejbt.2017.01.004

Moh, Y., \& Manaf, L. A. (2017). Solid waste management transformation and future challenges of source separation and recycling practice in Malaysia. Resources, Conservation and Recycling, 116, 1-14. https:// doi.org/10.1016/j.resconrec.2016.09.012

Nation, U. (2019). The Sustainable Development Goals Report 2019. United Nations.

Ongondo, F. O., Williams, I. D., \& Cherrett, T. J. (2011). How are WEEE doing? A global review of the management of electrical and electronic wastes. Waste Management, 31(4), 714-730. https://doi. org/10.1016/j.wasman.2010.10.023 
Qazi, W. A., Abushammala, M. F., \& Azam, M. H. (2018). Multi-criteria decision analysis of waste-to-energy technologies for municipal solid waste management in Sultanate of Oman. Waste Management \& Research, 36(7), 594-605. https://doi.org/10.1177/0734242X18777800

Rahman, N. I. A., Khoiry, M. A., Rahim, S., \& Basri, N. E. A. (2020). Review on current municipal solid waste management in Malaysia. International Journal of Disaster Recovery and Business Continuity, 11(1), 2229-2242.

Randazzo, L., Cusumano, A., Oliveri, G., Di Stefano, P., Renda, P., Perricone, M., \& Zarcone, G. (2018). Landfill site selection for municipal solid waste by using AHP method in GIS environment: Waste management decision-support in Sicily (Italy). Detritus, 2(1), 78-88. https://doi.org/10.31025/2611-4135/2018.13656

Saaty, T. L. (2008). Decision making with the analytic hierarchy process. International Journal of Services Sciences, 1(1), 83-98. https://doi.org/10.1504/IJSSCI.2008.017590

Samad, N. A. F. A., Jamin, N. A., \& Saleh, S. (2017). Torrefaction of municipal solid waste in Malaysia. Energy Procedia, 138, 313-318. https://doi.org/https://doi.org/10.1016/j.egypro.2017.10.106

Saraiva, A. B., Pacheco, E. B., Gomes, G. M., Visconte, L. L., Bernardo, C., Simões, C. L., \& Soares, A. G. (2016). Comparative lifecycle assessment of mango packaging made from a polyethylene/natural fibercomposite and from cardboard material. Journal of Cleaner Production, 139, 1168-1180. https://doi. org/10.1016/J.JCLEPRO.2016.08.135

Sarigiannis, D. A., Handakas, E. J., Karakitsios, S. P., \& Gotti, A. (2021). Life cycle assessment of municipal waste management options. Environmental Research, 193, Article 110307. https://doi.org/10.1016/j. envres.2020.110307

Schwenk, W. S., Donovan, T. M., Keeton, W. S., \& Nunery, J. S. (2012). Carbon storage, timber production, and biodiversity: Comparing ecosystem services with multi-criteria decision analysis. Ecological Applications, 22(5), 1612-1627.

Sekhon, P. S., \& Karthigesu, I. T. (2017). Awareness on health and safety among municipal workers on solid waste collections: A case study in Malaysia. Malaysian Journal of Public Health Medicine, 9, 19-27.

Subramanian, N., \& Ramanathan, R. (2012). A review of applications of analytic hierarchy process in operations management. International Journal of Production Economics, 138(2), 215-241. https://doi.org/https:// doi.org/10.1016/j.ijpe.2012.03.036

T’ing, L. C., Moorthy, K., Mei, C. Y., Yin, F. P., Ying, W. Z., Khong, C. W., Chern, G. Z., \& Lin, T. Z. (2020). Determinants of 3Rs behaviour in plastic usage: A study among Malaysians. Heliyon, 6(12), 1-11. https:// doi.org/10.1016/j.heliyon.2020.e05805

Torkayesh, A. E., Malmir, B., \& Asadabadi, M. R. (2021). Sustainable waste disposal technology selection: The stratified best-worst multi-criteria decision-making method. Waste Management, 122, 100-112. https:// doi.org/10.1016/j.wasman.2020.12.040

Torkayesh, S. E., Amiri, A., Iranizad, A., \& Torkayesh, A. E. (2020). Entropy based EDAS decision making model for neighborhood selection: A case study in istanbul. Journal of Industrial Engineering and Decision Making, 1(1), 1-11. https://doi.org/10.31181/jiedm200101001t 
van Ewijk, S., Stegemann, J. A., \& Ekins, P. (2017). Global life cycle paper flows, recycling metrics, and material efficiency. Journal of Industrial Ecology, 22(4), 686-693. https://doi.org/10.1111/jiec.12613

Vlachokostas, C., Michailidou, A. V., \& Achillas, C. (2021). Multi-criteria decision analysis towards promoting waste-to-energy management strategies: A critical review. Renewable and Sustainable Energy Reviews, 138, Article 110563. https://doi.org/10.1016/j.rser.2020.110563

Vukoje, M., \& Rožić, M. (2018). Various valorisation routes of paper intended for recycling - A Review. Cellulose Chemicstry and Technology, 52(7-8), 515-541.

Wong, Y. C., Al-Obaidi, K. M., \& Mahyuddin, N. (2018). Recycling of end-of-life vehicles (ELVs) for building products: Concept of processing framework from automotive to construction industries in Malaysia. Journal of Cleaner Production, 190, 285-302. https://doi.org/10.1016/j.jclepro.2018.04.145

Yadav, V., Kalbar, P. P., Karmakar, S., \& Dikshit, A. (2020). A two-stage multi-attribute decision-making model for selecting appropriate locations of waste transfer stations in urban centers. Waste Management, 114, 80-88. https://doi.org/10.1016/j.wasman.2020.05.024

Zainu, Z. A., \& Songip, A. R. (2017). Policies, challenges and strategies for municipal waste management in Malaysia. Journal of Science, Technology and Innovation Policy, 3(1), 10-14. https://doi.org/10.11113/ jostip.v3n1.18 